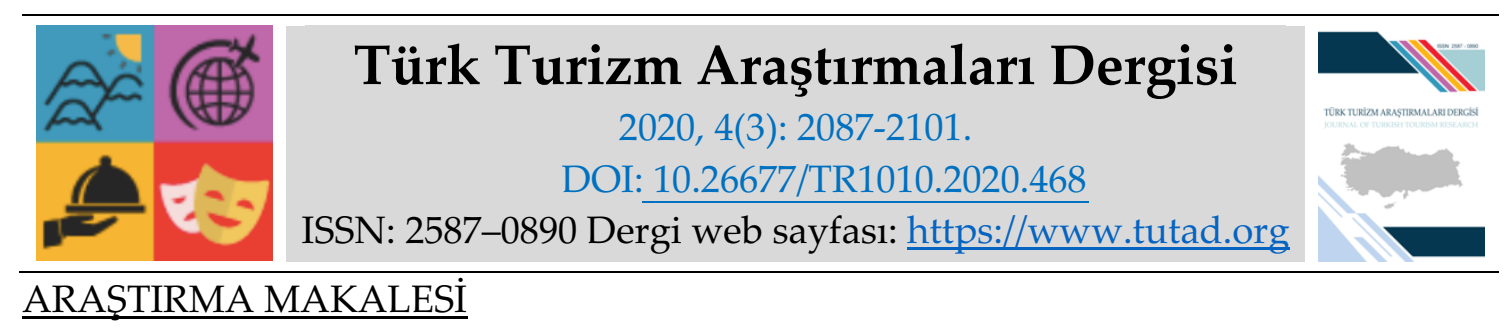

\title{
Farklı Aromatik Bitkilerle Marine Edilip Vakumlanarak Saklanan Dana Etlerinin Bazı Özelliklerinin İncelenmesi
}

Dr. Öğr. Üyesi İbrahim Tuğkan ŞEKER, Cumhuriyet Üniversitesi, Turizm Fakültesi, Sivas, eposta: tseker@cumhuriyet.edu.tr ORCID: https://orcid.org/0000-0003-3695-9750

Dr. Öğr. Üyesi Emre HASTAOĞLU, Cumhuriyet Üniversitesi, Turizm Fakültesi, Sivas, e-posta: ehastaoglu@cumhuriyet.edu.tr ORCID: https://orcid.org/0000-0001-8802-6632

Dr. Öğr. Üyesi Meryem GÖKSEL SARAÇ, Cumhuriyet Üniversitesi, Yıldızeli MYO, Sivas, eposta: mgoksel@cumhuriyet.edu.tr

ORCID: https://orcid.org/0000-0002-8190-2406

\section{Öz}

Et ve et ürünleri beslenmenin temel bileşenlerindendir. Gerek taze gerekse işlenmiş et ürünleri günlük diyetimizin önemli bir kısmını oluşturmaktadır. Günümüzde değişen sosyoekonomik durum ile damak tatları da değişiklik göstermiş ve taze et tüketiminde süregelen alışkanlıklar farklılaşmaya başlamıştır. Etin direk pişirilmesi yerine marine edilerek gevrekleştirilmiş et tüketimi, evde ve ev dışı tüketimde oldukça yaygınlaşmıştır. Bu çalışma kapsamında, birçok fenolik bileşik ve antimikrobiyal maddeyi bünyesinde barındıran kekik, sumak, defneyaprağı ve biberiye marinasyon işleminde kullanılmıştır. Dana sırt etleri farklı doğal aromatik bitkilerle \%1,5 ve 3 oranlarında muamele edilip vakum ambalaj yapılarak dinlendirilmiştir. 14 gün boyunca $+2^{\circ} \mathrm{C}^{\prime}$ de soğutucuda dinlendirilen etlerin 7 . ve 14 . günde kimyasal ve duyusal özellikleri incelenmiştir. Yapılan analizler sonucunda etlerin $\mathrm{pH}$ ve yağ oksidasyon düzeylerinde kontrol örneğine göre istatistiksel açıdan farklılıklar gözlenmiştir. Özellikle sumak ilave edilen örneklerde $\mathrm{pH}$ düşüşü önemli ölçüde olmuştur. Sonuçlar duyusal açıdan değerlendirildiğinde, $\% 1,5$ defneyaprağı ile marine edilen örnekler 7. gün ve 14. gün sonunda en beğenilen ürün olurken, 14. gün sonunda kontrol örneği en az beğenilen ürün olmuştur. Kekik, sumak, defneyaprağ 1 ve biberiye marinasyonu ile dana etlerinin daha tercih edilebilir lezzette olduğu belirlenmiştir.

Anahtar Kelimeler: Aromatik Bitkiler, Marinasyon, Duyusal Analiz.

Makale Gönderme Tarihi: 09.03.2020

Makale Kabul Tarihi: 04.07 .2020

Önerilen Atıf:

Şeker, İ. T., Hastaoğlu, E. ve Göksel Saraç, M. (2020). Farklı Aromatik Bitkilerle Marine Edilip Vakumlanarak Saklanan Dana Etlerinin Bazı Özelliklerinin İncelenmesi, Türk Turizm Araştırmaları Dergisi, 4(3): 2087-2101.

(C) 2020 Türk Turizm Araştırmaları Dergisi. 


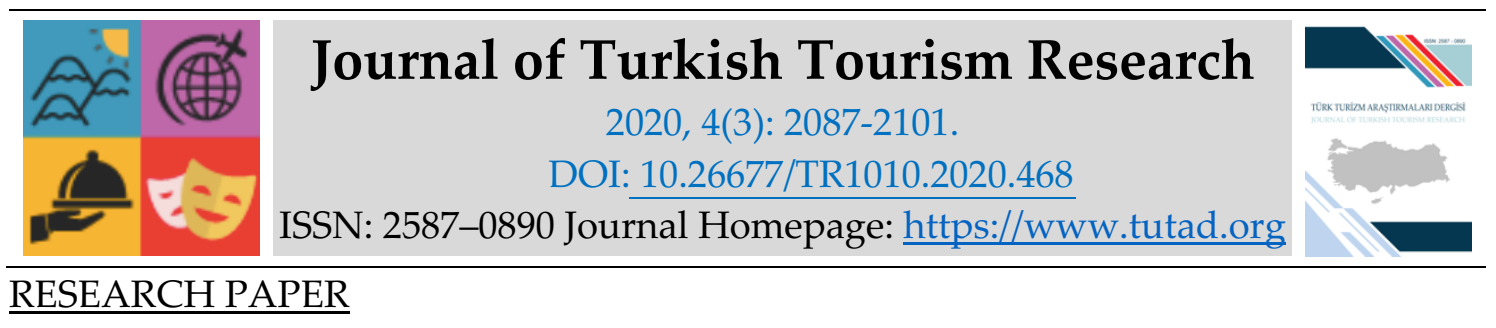

\title{
Investigation of Some Properties of Beef Which is Vacuumed and Marinated with Different Aromatic Plants
}

Assistant Prof. Dr. İbrahim Tuğkan ŞEKER, Cumhuriyet University, Faculty of Tourism, Sivas, email: tseker@cumhuriyet.edu.tr

ORCID: https://orcid.org/0000-0003-3695-9750

Assistant Prof. Dr. Emre HASTAOĞLU, Cumhuriyet University, Faculty of Tourism, Sivas, email: ehastaoglu@cumhuriyet.edu.tr

ORCID: https://orcid.org/0000-0001-8802-6632

Assistant Prof. Dr. Meryem GÖKSEL SARAÇ, Cumhuriyet University, Yıldizeli Vocational School, Sivas, e-mail: mgoksel@cumhuriyet.edu.tr

ORCID: https://orcid.org/0000-0002-8190-2406

\begin{abstract}
Meat and meat products are essential components of nutrition. Both fresh and processed meat products constitute an important part of our daily diet. Today, the changing socioeconomic status and taste have also changed and the ongoing habits in fresh meat consumption have started to differ. The consumption of marinated and crunched meat rather than direct cooking of meat has become quite common at home and outside consumption. In this study, thyme, sumac, bay leaf and rosemary, which contain many phenolic compounds and antimicrobial substances, were used in the marination process. Beef rib meats were treated with different natural aromatic plants in $1.5 \%$ and 3 ratios and rested by vacuum packaging. The chemical and sensory properties of the meats resting at $+2^{\circ} \mathrm{C}$ for 14 days were examined on the 0th 7th and 14th days. As a result of the analysis, statistical differences were observed in the $\mathrm{pH}$ and fat oxidation levels of the meats according to the control sample. Especially in samples with added sumac, $\mathrm{pH}$ decrease was significantly. When the results were evaluated from the sensory point of view, samples marinated with $1.5 \%$ bay leaf became the most liked product at the end of the 7 th and 14th days, while the control sample was the least liked at the end of the 14th day. It has been determined that beef meat has a more preferable flavor with thyme, sumac, bay leaf and rosemary marinating.
\end{abstract}

Keywords: Aromatic Plants, Marination, Sensory Analyses.

Received: 09.03.2020

Accepted: 04.07.2020

Suggested Citation:

Şeker, İ. T., Hastaoğlu, E. and Göksel Saraç, M. (2020). Investigation of Some Properties of Beef Which is Vacuumed and Marinated with Different Aromatic PlantsJournal of Turkish Tourism Research, 4(3): 2087-2101.

(C) 2020 Türk Turizm Araştırmaları Dergisi. 


\section{Gíriş}

Et ve et ürünleri kimyasal yapıları sebebiyle çok kolay bozulabilen gıdalardır. İçerdikleri besin bileşenleri ve yüksek su miktarından dolayı fiziksel, kimyasal ve mikrobiyolojik olarak her türlü değişime açıktır. Doğru şartlarda işlenmeyen veya depolanmayan etlerde her türlü bozulma görülebilir. İnsan sağlığını tehdit edecek boyutlara çıkabilecek bu bozulmalar, bazı uygulamalar ile engellenebilmektedir. Besleyici değeri yüksek olan et ve et ürünlerinin uzun süre muhafaza edilmesi çalışmaları neredeyse insanlık tarihiyle yaşıttır. Ateşin keşfi ile insanoğlunun mutfak kültürü çok farklı bir yere taşınmış ve insanlar avladıkları hayvan etlerini pişirmeyi öğrenmişlerdir. Pişmiş etlerin kullanılması ve saklanması hayatı kolaylaştırırken taze etlerin doğru şekilde saklanması ve çözüm bulunması gereken en önemli problemlerden olmuştur. İlerleyen zamanlarda, soğutucu sistemlerin keşfi, taze etlerin saklanabilmesine olanak sağlamıştır.

Etin raf ömrü süresi çeşitli etkenlere bağlı olarak değişkenlik göstermektedir. Bu etkenler arasında, sıcaklık, oksijen, endojen enzimler, su aktivitesi, ışık ve ürünün başlangıçtaki mikroorganizma yükü sayılabilir. Bu faktörlerin etkisi ile et ve et ürünlerinin lezzeti ve renginde arzu edilmeyen değişiklikler meydana gelmektedir (Faustmann ve Cassens, 1990). Et ve et ürünleri su aktivitesinin yüksek olması ve besin içeriklerinin zengin olması nedeniyle mikroorganizmaların gelişmesi için uygun bir ortamdır bu nedenle gıda kalitesi ve güvenliğinin sağlanması için etkili muhafaza tekniklerinin kullanılması gerektirmektedir (Aymerich ve ark., 2008). Bu amaçla et ürünleri üretiminde doğal veya yapay çeşitli katkı maddeleri kullanılabilmektedir. Ancak taze ette katkı maddesi kullanılamadığından etlerin muhafaza yöntemlerinin, modifiye/kontrollü atmosfer paketleme (MAP/KAP), vakum teknolojileri veya soğutarak muhafaza (soğuk/donuk) teknikleri ile sınırlı olduğu bildirilmiştir (Zhou vd., 2010; EFSA, 2011).

Et ve et ürünlerinde bulunan hayvansal yağ, kolesterol, sentetik antioksidanlar ve antimikrobiyallerin yarattı̆̆ı dejeneratif rahatsızlıklardan dolayı günümüzde tüketicilerin et ve et ürünleri tüketiminde hassas ve kaygılı olduğu görülmektedir (Serrano vd., 2007). Araştırmacılar, yenilenmiş, daha sağlıklı hale getirilmiş ve daha uzun raf ömürlü et ürünlerini tüketime sunabilmek için etlerin marine edilerek, raf ömrünü artırmaya çalışmakta, bu amaçla, fındık, meyve, sebze, baharat ve bitkisel kökenli ürünlerin kullanımına ilgi göstermektedir (Hastaoğlu vd., 2019)

Etlerin yumuşatılması, tat ve aromasının geliştirilmesi ve raf ömrünün uzatılması için çeşniler ve katkı maddeleriyle hazırlanmış asidik sıvı ile belirli süre temas edilmesine marinasyon denilmektedir (Doğan, 2019). Marinasyon, diğer adıyla terbiyeleme, kolay uygulanabilmesi ve marinasyon sıvisının kolay temin edilebilmesinden dolayı geleneksel metotlar ile birlikte uygulanabilen bir tekniktir. Bununla birlikte son zamanlarda donanımlı et işleme tesislerinin kurulması ve yeni marinasyon ekipmanlarının geliştirilmesi ile marinasyon tekniği değişime uğramış ve geleneksel yöntemlerdeki işçilik, süre, katkı maddesi gibi kayıplar en aza indirilmiştir (Lemos vd., 1999; Smith, 1999; Woods ve Church, 1999; Xargayo vd., 2001). Et marinasyonu etin fonksiyonel özelliklerini artırması veya aroma bileşenlerini güçlendirmesi gibi et kalitesini geliştiren yönleri nedeniyle restoranlar tarafından çok kullanılır. ABD'de kemiksiz ve derisiz tavuk göğüs eti vakum tamburlama ile muamale edilir çünkü marinasyon sırasında daha fazla marinat dokulara girer. Bu da hem kaliteyi artırır hem de ekonomik fayda sağlamış olur (Smith ve Acton, 2001). Diğer taraftan yapılan çalışmalar, ete uygulanan marinasyonun pişirme esnasında ette oluşabilecek heterosiktlik aromatik amin oluşumunu engellediğini göstermektedir (Iwasaki vd., 2010). 
Teknolojinin gelişmesi ile gıda endüstrisinde yapay katkı maddelerinin kullanımı artmış ancak sağlık üzerindeki yan etkilerini ve mikroorganizmaların yapay antimikrobiyallere karşı direnç oluşturduğu ortaya konmuştur. Bu nedenler, tıbbi ve aromatik bitkilerin gıdalarda, hayvan yemlerinde ve organik tarım uygulamalarında kullanımı ile ilgili çalışmaları hızlandırmıştır (Bayaz, 2014).

Yapılan bir çalışmada, ette oluşan oksidasyonu engellemek için, üzüm çekirdeği, nar, tarçın, yeşil çay ve ısırgan otu gibi doğal bitkilerin yapay antioksidanların yerine doğal olarak kullanılabileceği bildirilmiştir (Babür ve Gürbüz, 2015). Kahraman ve ark (2010) tarafından sitrik asit (limon), laktik asit (yoğurt) ve asetik asit (sirke) gibi organik asitler ile et örnekleri marine edilmiş ve kullanılan bileşenlerin et kalitesi üzerine etkisi incelenmiştir. Çalışmaya göre, organik asidin hücre içine alındığında dissosiye olduğu ve hücre içi asit düzeyini artırması sonucu etin su tutma kapasitesinin arttığı ve et ürün kalitesine katkı sağladığı belirtilmiştir.

Yapılan başka bir çalışmada ise doğal nar ekşisi, erik ekşisi ve limon tuzu ile marine edilen blok et ve kıyılmış etlerde toplam aerobik mezofilik mikroorganizma sayılarının azaldığını ve nar ekşisi, erik ekşisi ve limon tuzunun antimikrobiyal etkisinin olduğu belirtilmiştir (Yapar, 2006). Diğer taraftan kekikten elde edilen Thymus vulgaris, Thymus mastichina, Thymus caespititius, ve Thymus camphorate'ın $\alpha$-tocopherol ve Butil Hidroksi Toluen (BHT) gibi yüksek antioksidan aktiviteye sahip oldukları belirlenmiştir (Miguel vd., 2004).

Akgül ve Ayar (1993)'ın yapmış oldukları bir çalışmada, ayçiçek yağı üzerinde Türkiye'de yetiştirilen 31 çeşit aromatik bitkinin antioksidan etkisi araştırılmış ve biberiyenin en yüksek antioksidan aktiviteye sahip olduğu, biberiyeden sonra adaçayı, sumak ve kekik geldiği belirtilmiştir. Farklı bitkisel yağlar üzerine biberiye, adaçayı, kekik, mercanköşk, zencefil ekstraktlarının antioksidasyon stabilitesi incelenmiş ve etkili sonuçlar bulunmuştur (Yanishlieva ve Marinova 2001). Ticari olarak biberiye ekstraktı güçlü antioksidan aktivitesinden dolayı et ürünlerinde kullanılmaktadır (Vazgeçer vd., 2005). Özcan ve Sağdıç (2003), yaptıkları çalışmada 16 bitki (anason, rezene, kimyon, adaçayı, fesleğen, dereotu, defne, nane, mercanköşk, pickling herb, biberiye, dalamagia adaçayı, savory (kekik), sumak, thyme (kekik), kaya koruğu (seafennel) hidrosollerinin farklı bakterilerin gelişimleri üzerindeki etkilerini araştırmışlardır. Çalışmaya göre, anason, kimyon, mercanköşk, savory (kekik), thyme (kekik) hidrosollerinin kullanılan bakteriler üzerinde inhibisyon etki gösterdiği belirlenmiştir. İnkübasyon süresince tüm bakteriler üzerinde en yüksek antimikrobiyal etkinin mercanköşk ve savory (kekik) hidrosollerine ait olduğu, anason, kimyon ve thyme (kekik) hidrosollerinin ise ancak bakterilerin bir kismı üzerinde etkili olduğu belirlenmiştir.

Etlerin doğru yöntemlerle işlenmemesi veya saklanmaması durumunda öncelikli olarak mikrobiyal bozulma gerçekleşir ve insan sağlığını tehdit edecek patojen mikroorganizmalar gelişir. Kimyasal olarak et yağında ransidite olarak ifade edilen acılaşma gerçekleşir ve farklı toksik bileşikler açığa çıkar. Etin renginde, kokusunda ve tadında istenmeyen değişiklikler meydana gelmektedir. Ette meydana gelebilen bu tür değişiklikler çeşitli gıda analiz yöntemleriyle açıklanabilmektedir. Ette gelişen mikroorganizmalar mikrobiyolojik tekniklerle, ette hissedilen acılaşma reaksiyon sonucu oluşan tiyobarbitürik asit varlığının miktar tespiti ile açılanabilmektedir (Karabudak, 2002).

Bu çalışma ile Türk mutfağında sık kullanılan kekik, biberiye, defneyaprağı ve tane sumağın et marinasyonunda oluşturdukları etkiler incelenmiştir. Bu amaçla, $1 \mathrm{~cm}$ kalınlığında dilimlenmiş dana sırt etleri (longissimus dorsi-LD) \%1,5 oranında tuz ile muamele edildikten sonra farklı örneklere farklı miktarlarda kekik, biberiye, defneyaprağı ve tane sumak eklenerek vakumlanmış ve $+2^{\circ} \mathrm{C}^{\prime}$ de depolanmıştır. Depolamanın 7. ve 14. gününde vakum ambalajından çıkarılan etler 
fiziksel (pH), kimyasal (tiyobarbütirik asit-TBA) analizler yapılmıştır. Ardından örnekler kömür döküm ızgarada pişirilerek duyusal analizleri gerçekleştirilmiştir. Duyusal analiz sonuçları Çok Kriterli Karar Verme Yöntemi (SAW-TOPSİS) testlerine tabi tutulmuştur. Tüm sonuçlar SPSS programı ile istatiksel olarak değerlendirilmiştir.

\section{MATERYAL ve METOT}

Çalışma kapsamında kesimden 24 saat sonra post-mortem sürecini tamamlamış etler kullanılmış ve etler yerel bir kesimhaneden temin edilmiştir. Kullanılan etler, sığırın sırt kaslarından (longissimus dorsi-LD), hijyen şartlarına dikkat edilerek hazırlanmış ve aynı gün soğuk zincirle Cumhuriyet Üniversitesi Turizm Fakültesi Gastronomi ve Mutfak Sanatları Bölümü uygulama mutfağına getirilmiştir. Blok etler, mikrobiyal kontaminasyonu önlemek amacıyla, hijyenik koşullara dikkat edilerek 0,5-1,0 cm kalınlığında dilimlenmiştir. Marinasyonda kullanılacak bitkiler, kekik, biberiye, defneyaprağı ve tane sumak, yerel bir baharat firmasından temin edilmiştir.

Aromatik bitkilerin uygulama miktarları daha önce yapılan araştırmalara paralel olarak et miktarı üzerinden $\% 1,5$ ve \%3 olarak tespit edilmiştir. Tespit edilen miktardaki aromatik bitkiler, etin her iki yüzeyine eşit olacak şekilde kuru marinasyon ve masaj yöntemi kullanılarak el yordamıyla uygulanmıştır. Polietilen vakum poşetlerine yerleştirilen etlerin tüm havası alınarak vakumlanmış ve anaerobik koşullarda 14 gün $+2^{\circ} \mathrm{C}^{\prime}$ de depolanmıştır. Analize hazır hale gelen örneklerin 0,7 ve 14.günlerde kimyasal ve duyusal analizleri yapılmıştır. Örnek miktarı üzerinden \%1,5 oranında iyotlu tuz kullanılarak örnekler aynı anda ve aynı sürede döküm ızgarada pişirilerek panelistler tarafından duyusal analiz yapılmıştır. Her analiz günü için ayrı örnek vakumlanmış olup, vakumu açılan örneklerin analizleri tamamlandıktan sonra tekrar kullanılmamıştır.

\section{pH Analizi}

Et örneklerinde pH tayini TS 3136 ISO 2917 numaralı pH Ölçülmesi Standardı'na göre yapılmıştır.

\section{TBA (tiyobarbütürikasit) Sayısı Analizi}

Tiyobarbitürik asit tayini için Tarlagids ve ark.'nın kullandıkları yönteme göre destilasyon tekniği ile toplanan destilat, optik yoğunluğu spektrofotometrede $538 \mu \mathrm{m}^{\prime}$ de standart tanık (tanık yerine şahit daha uygun bir ifade) çözeltiye karşı okunmuş ve TBA değeri (mg malonaldehit $/ \mathrm{kg}$ örnek) $=7,8 \times$ absorbans değeri şeklinde hesaplanmıştır.

\section{Duyusal Analizler}

Farklı aromatik bitkiler ile marine edilmiş et örnekleri \%1,5 tuz ilave edildikten sonra tüm örnekler aynı anda ve aynı sürede, Cumhuriyet Üniversitesi Turizm Fakültesi Gastronomi ve Mutfak Sanatları Bölümü uygulama mutfağında odun ateşi ile döküm ızgarada pişirilerek duyusal analizleri yapılmıştır. Duyusal analizler için eğitimli 30 panelistten destek alınmıştır. Analizler hedonik skala kullanılarak 1-9 puan aralığında koku, sertlik, sululuk, ekşili, acılık, 
tuzluluk, aroma ve genel beğeni başlıkları ile değerlendirilmiştir. Tablo 1'de değerlendirme formu verilmiştir. Elde edilen sonuçlar çok kriterli karar verme yöntemi ile incelenmiştir.

Tablo 1. Marine Et Örneklerinin Duyusal Değerlendirme Formu

\begin{tabular}{|c|c|c|c|c|c|c|c|}
\hline \multicolumn{2}{|c|}{ Panelistin Adı-Soyadı: } & \multicolumn{3}{|c|}{ Panel Tarihi: } & \multicolumn{3}{|c|}{ Örnek Kodu: } \\
\hline \multicolumn{8}{|c|}{\begin{tabular}{|l|l|} 
KOKU & \\
\end{tabular}} \\
\hline \multicolumn{2}{|l|}{ Hoşa giden } & \multicolumn{2}{|c|}{ Orta } & & & \multicolumn{2}{|c|}{ Hoşa Gitmeyen } \\
\hline \begin{tabular}{|ll}
$(9)$ & $(8)$ \\
\end{tabular} & (7) & (6) & $(5)$ & (4) & (3) & $(2)$ & $(1)$ \\
\hline \multicolumn{8}{|l|}{\begin{tabular}{|l|} 
SERTLIK \\
\end{tabular}} \\
\hline Yumuşak & & \multicolumn{2}{|c|}{ Orta } & & \multicolumn{2}{|r|}{ Sert } & \\
\hline (9) & (7) & (6) & $(5)$ & (4) & (3) & $(2)$ & (1) \\
\hline \multicolumn{8}{|l|}{ SULULUK } \\
\hline \multicolumn{2}{|l|}{ Hoşa giden } & \multicolumn{2}{|c|}{ Orta } & & & \multicolumn{2}{|c|}{ Hoşa Gitmeyen } \\
\hline 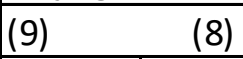 & (7) & (6) & (5) & (4) & (3) & $(2)$ & $(1)$ \\
\hline \multicolumn{8}{|l|}{ EKŞiLik } \\
\hline \multicolumn{2}{|l|}{ Hoşa giden } & \multicolumn{2}{|c|}{ Orta } & & & \multicolumn{2}{|c|}{ Hoşa Gitmeyen } \\
\hline \begin{tabular}{|ll}
$(9)$ & $(8)$ \\
\end{tabular} & (7) & (6) & (5) & (4) & (3) & $(2)$ & $(1)$ \\
\hline \multicolumn{8}{|l|}{\begin{tabular}{l|l} 
ACILIK & \\
\end{tabular}} \\
\hline \multicolumn{2}{|l|}{ Hoşa giden } & \multicolumn{2}{|c|}{ Orta } & & & \multicolumn{2}{|c|}{ Hoşa Gitmeyen } \\
\hline \begin{tabular}{|ll}
$(9)$ & $(8)$ \\
\end{tabular} & (7) & (6) & $(5)$ & (4) & (3) & $(2)$ & $(1)$ \\
\hline \multicolumn{8}{|l|}{ TUZLULUK } \\
\hline \multicolumn{2}{|l|}{ Hoşa giden } & \multicolumn{2}{|c|}{ Orta } & & & \multicolumn{2}{|c|}{ Hoşa Gitmeyen } \\
\hline \begin{tabular}{|ll}
$(9)$ & $(8)$ \\
\end{tabular} & (7) & (6) & (5) & (4) & (3) & $(2)$ & $(1)$ \\
\hline \multicolumn{8}{|l|}{ AROMA } \\
\hline Hoşa giden & & \multicolumn{2}{|c|}{ Orta } & & & \multicolumn{2}{|c|}{ Hoşa Gitmeyen } \\
\hline 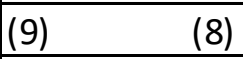 & (7) & (6) & $(5)$ & (4) & (3) & $(2)$ & $(1)$ \\
\hline \multicolumn{8}{|l|}{ GENEL BEĞENI } \\
\hline Hoş & & \multicolumn{2}{|c|}{ Orta } & & & & \\
\hline (9) & (7) & (6) & (5) & (4) & (3) & (2) & $(1)$ \\
\hline
\end{tabular}

Duyusal analiz sonuçları çok kriterli karar verme yöntemleri kullanılarak değerlendirilmiştir. Çok kriterli karar verme yöntemlerinden olan SAW (Basit Toplamlı Ağırlıklandırma) yöntemi duyusal değerlendirme amacıyla kullanılmıştır. Birden fazla parametrenin değerlendirildiği ve çok kriterin bulunduğu duyusal değerlendirmeler arasından en tercih edilen ürünü bulmak için SAW yöntemi kullanılmaktadır.

\section{Basit Toplamlı Ağırlıklandırma (SAW) Yöntemi:}

SAW yöntemi portföy seçim uygulamasında çalışılarak Churchman ve Ackoff (1954) tarafından kullanılmaya başlanmıştır. Simple Additive Weighting olarak ifade edilen SAW yöntemi dilimize Basit Toplamlı Ağırlıklandırma olarak geçmiştir. SAW yöntemi diğer çok kriterli karar verme yöntemleri gibi çok kriterin bulunduğu seçimlerde ürün tercih sıralaması yapımında yaygın kullanımı olan yöntemlerdendir. SAW yöntemi algoritması iki basamaktan oluşmaktadır. 
SAW uygulaması ilk basamağı karar matrisinin oluşturulmasıdır. Bu aşamada aşağıda verilen formülle hesaplama yapılmaktadır, formülde; $m$ alternatif sayısını, $n$ kriter sayısını, $i$ satırı ve $j$ sütunu ifade etmektedir.

$$
r i j=\left\{\begin{array}{lll}
\frac{x i j}{\max x i j} & i=1, \ldots, m ; & j=1, \ldots, n \text { fayda kriteri } i c ̧ i n \\
\frac{\min x i j}{x i j} & i=1, \ldots, m ; & j=1, \ldots, n \text { fayda kriteri } i c ̧ i n
\end{array}\right.
$$

İkinci aşamada ise alternatiflerin toplam tercih değerleri aşağıdaki denklem yardımıyla hesaplanmaktadır.

$$
S i=\sum_{\mathrm{j}=1}^{\mathrm{m}} \text { wjrij }
$$

Formülde $j$ kriterinin ağırlığını ve $S$ alternatif tercih değerini göstermektedir.

Elde edilen sonuçlar neticesinde örneklerin Si değerleri büyükten küçüğe doğru sırlamaya konur ve en yüksek değere sahip olan alternatif en beğenilen ürünü ifade etmektedir.

\section{İstatistiksel Analiz}

Elde edilen veriler SPSS paket programı kullanılarak, örnek grupları arasındaki farklar One-Way Anova testi ile belirlenmiş, istatistiksel olarak önemli olan farklar Tukey HSD (Honestly Significant Difference) testine tabi tutulmuşlardır.

\section{BULGULAR}

Farklı aromatik bitkilerin farklı oranlarda ilave edilmesiyle marine edilen dana etlerinin $\mathrm{pH}$ değişimleri Tablo 2.'de verilmiştir.

\begin{tabular}{|c|c|c|c|}
\hline & \multicolumn{3}{|c|}{$\mathrm{pH}$} \\
\hline & 0. gün & 7. gün & 14. gün \\
\hline Kontrol & $5,46^{\mathrm{Ac}}$ & $5,36^{\mathrm{Cb}}$ & $5,25^{\mathrm{Da}}$ \\
\hline Sumak \% 1.5 & $5,46^{\mathrm{Ac}}$ & $4,32^{\mathrm{Ba}}$ & $4,99 \mathrm{Bb}$ \\
\hline Sumak \% 3 & $5,46^{\mathrm{Ac}}$ & $4,04^{\mathrm{Aa}}$ & $4,19^{\mathrm{Ab}}$ \\
\hline Defneyaprağ1 \% 1.5 & $5,46^{\mathrm{Ab}}$ & $5,41^{\mathrm{Db}}$ & $5,19 \mathrm{Ca}$ \\
\hline Defneyaprağ1 $\% 3.0$ & $5,46^{\mathrm{Ab}}$ & $5,67 \mathrm{Ec}$ & $5,17 \mathrm{Ca}$ \\
\hline Kekik \% 1.5 & $5,46^{\mathrm{Ab}}$ & $5,31^{\mathrm{Ca}}$ & $5,56^{\mathrm{Ec}}$ \\
\hline Kekik \% 3.0 & $5,46^{\mathrm{Ac}}$ & $5,38^{\mathrm{Cb}}$ & $5,27 \mathrm{Da}$ \\
\hline Biberiye \% 1.5 & $5,46^{\mathrm{Ac}}$ & $5,32^{\mathrm{Cb}}$ & $5,29 \mathrm{Da}$ \\
\hline Biberiye \% 3.0 & $5,46^{\mathrm{Ac}}$ & $5,37^{\mathrm{Cb}}$ & $5,30^{\mathrm{Da}}$ \\
\hline
\end{tabular}

Tablo 2. Farklı aromatik bitkilerin ilavesiyle marine edilen dana etlerinin pH değişimleri

a-c Aynı satırda farklı harflere sahip örnekler arasındaki fark önemlidir $(\mathrm{p}<0.05)$

A-E Aynı sütunda farklı harflere sahip örnekler arasındaki fark önemlidir $(p<0.05)$ 
$\mathrm{pH}$ ortamda mevcut olan hidrojen iyon konsantrasyonun ölçümüdür. Et üretimi amaciyla kesimi yapılan sağlıklı kasaplık hayvanın kesiminin gerçekleştirildiği anda kas dokularının pH'sı 7,0-7,2 arasında değişir. Kesimden hemen sonra oksijensiz şartlarda kaslarda başlayan bir kısım biyokimyasal reaksiyonlar sonucunda meydana gelen laktik asit miktarının artışıyla $\mathrm{pH}^{\prime} \mathrm{da}$ değişim meydana gelir. Kesimden sonra ette pH'nın düşüşüne bağlı olarak etin kendine özgü rengi, tekstürü ve kıvamı oluşur (Öztan, 2018).

Etlerde $\mathrm{pH}$ değişimi etin hangi ürüne işleneceğine karar verdiği gibi aynı zamanda etin mikrobiyolojik olarak stabilitesini de belirler. Etlerde $\mathrm{pH}$ değerinin düşmesi ile ette gevreklik artarken aynı zamanda mikroorganizmaların gelişimi de sınırlanır. Ancak çok aşırı düşmelerde etin su tutma kapasitesi düşeceğinden dolayı duyusal lezzet kayıpları görülebilmektedir. Sonuçlar incelendiğinde ilave edilen aromatik bitkilerin tamamında $\mathrm{pH}$ düşüşü söz konusudur. En düşük pH değeri sumakla marine edilmiş etlerde tespit edilmiştir. Türkiye'de yetiştirilen sumakların ortalama pH'ları 2.45 civarındadır. Bundan dolayı sumak ilavesi ile örneklerde ciddi bir pH düşüşü görülmüştür. Düşük pH ile mikrobiyolojik stabilite ve gevreklik sağlanırken, duyusal değerlendirme parametrelerinin bazılarında azalma görülmüştür.

Gıdalardaki yağlar ile oksijen arasında otoksidasyon (kendiliğinden oluşan) reaksiyonlar gerçekleşir. Özellikle et ve et ürünlerinde kalitenin düşmesine neden olan bu reaksiyonlar gıda endüstrisi açısından istemeyen reaksiyonlardır. Etteki kalitenin düşmesi, duyusal özelliklerinin bozulması ve toksik olabilecek bazı bileşiklerin parçalanması şeklinde olabilir. Ette gerçekleşen oksidasyon ürünlerinin tiyobarbütirik asit ile renginin değiştiği görülmüştür. Yağ asitlerinin otoksidasyonu ile oluşan bu bileşiklere malonaldehit denir ve glasial asitle hazırlanan 2tiobarbitürik asit çözeltisi, malondialdehitlerle renk oluşumuna neden olarak oksiatif ransidite düzeyinin saptanmasını sağlar (Schmedes, 1989).

Farklı aromatik bitkilerin farklı oranlarda ilave edilmesiyle marine edilen dana etlerinde oluşan TBA (Tiyobarbiturik asit) oluşumu Tablo 3'de verilmiştir.

Tablo 3. Farklı Aromatik Bitkilerin İlavesiyle Marine Edilen Dana Etlerinde Tespit Edilen TBA Miktarları

TBA (mgMA/kg örnek)

\begin{tabular}{|c|c|c|c|}
\hline & 0.gün & 7.gün & 14.gün \\
\hline Kontrol & $0,3276 \mathrm{Aa}$ & $0,3354^{\mathrm{Aa}}$ & $0,4212^{\mathrm{Ab}}$ \\
\hline Sumak \% 1.5 & $0,3276^{\mathrm{Aa}}$ & $0,3680^{\mathrm{Bb}}$ & $0,6660^{\mathrm{Ec}}$ \\
\hline Sumak \% 3 & $0,3276^{\mathrm{Aa}}$ & $0,3808^{\mathrm{Cb}}$ & $0,4686^{\mathrm{Bc}}$ \\
\hline Defneyaprağ $1 \% 1.5$ & $0,3276^{\mathrm{Aa}}$ & $0,3978^{\mathrm{Cb}}$ & $0,4542^{\mathrm{Bc}}$ \\
\hline Defneyaprağ $1 \% 3.0$ & $0,3276^{\mathrm{Aa}}$ & $0,6204^{\mathrm{Fb}}$ & $0,9864^{\mathrm{Fc}}$ \\
\hline Kekik \% 1.5 & $0,3276^{\mathrm{Aa}}$ & $0,4318^{\mathrm{Db}}$ & $0,6290^{\mathrm{Dc}}$ \\
\hline Kekik \% 3.0 & $0,3276^{\mathrm{Aa}}$ & $0,5772^{\mathrm{Eb}}$ & $0,6162^{\mathrm{Dc}}$ \\
\hline Biberiye \% 1.5 & $0,3276^{\mathrm{Aa}}$ & $0,4042^{\mathrm{Cb}}$ & $0,4992^{\mathrm{Cc}}$ \\
\hline Biberiye \% 3.0 & $0,3276^{\mathrm{Aa}}$ & $0,3524^{\mathrm{Ba}}$ & $0,4574^{\mathrm{Bc}}$ \\
\hline
\end{tabular}


Etlerin depolanma sürecinde TBA oluşumu kaçınılmazdır. TBA değerleri ile hayvansal gıdalardaki ransiditenin belirlenmesi arasında yüksek korelasyon elde edilmiştir. TBA aynı zamanda aşırı pişirme sonucu oluşan tat kayıpları ile de yüksek korelasyon vermiştir. Aşırı pişmiş tat (Warmed Over Flaover) kürlenmeden pişirilmiş et ürünlerinde görülen lezzet bozulmasına verilen isimdir ve çoklu doymamış yă̆ asitleri ve fosfolipitlerin oksidasyonu sonucu oluşan son ürünlerle ilgilidir.

Fernandez vd. (1997)'nin yaptığı çalışmada, TBA değerleri, sı̆̆ır ve/veya domuz eti için 0,3-1, tavuk eti için 1 veya 2 ve hindi eti için 3'ten fazla ise okside olmuş lezzet bozulması duyusal olarak fark edilebilir sınırı aşmışlardır. Bununla beraber bu aralık değerleri TBA testi hayvanın cinsi, beslenme şekli, yaşı, etin çiğ veya pişirilmiş olması ve uygulanan prosedür gibi birçok faktörden etkilendiği için genel referans değerleri olarak kabul edilemezler. Çalışmamız bu sınırların altında kaldığı görülmektedir.

Yapılan çalışmada depolama süresince TBA değerlerinin artış göstermesi normal bir durumdur. Çünkü et ve et ürünlerinde depolama esnasında belirli miktarlarda oksidasyon gerçekleşir ve TBA miktarında artış gözlenmektedir. Analizler incelendiğinde kabul edilebilir sınırlar içinde olduğu görülmektedir. Kontrol grubundaki TBA artışı, aromatik bitkilerle marine edilmiş örneklerden daha düşüktür. Bunun sebebinin, ilave edilen bitkilerden kaynaklı olduğu düşünülmektedir. Defneyaprağının kütlesel olarak \%1.5 oranında ilave edilen örneğin 14.gün depolama sonrası TBA miktarı, kontrole en yakın sonuç olduğu görülebilmektedir. Ancak defneyaprağı \%3 oranında ilave edilmesi TBA miktarını en yüksek seviyeye çıkarmıştır.

Duyusal analizler hedonik skala kullanılarak 1-9 puan aralığında koku, sertlik, sululuk, ekşili, acılık, tuzluluk, aroma ve genel beğeni başlıkları ile değerlendirilmiştir. Şekil 1'de örneklerin 7. günündeki duyusal analiz sonuçları verilmiştir. Örneklerin 14.gününde duyusal analiz sonuçları Şekil 2'de verilmiştir. 
Şekil 1. Depolamanın 7. Gününde Örneklerin Duyusal Analiz Sonuçları*
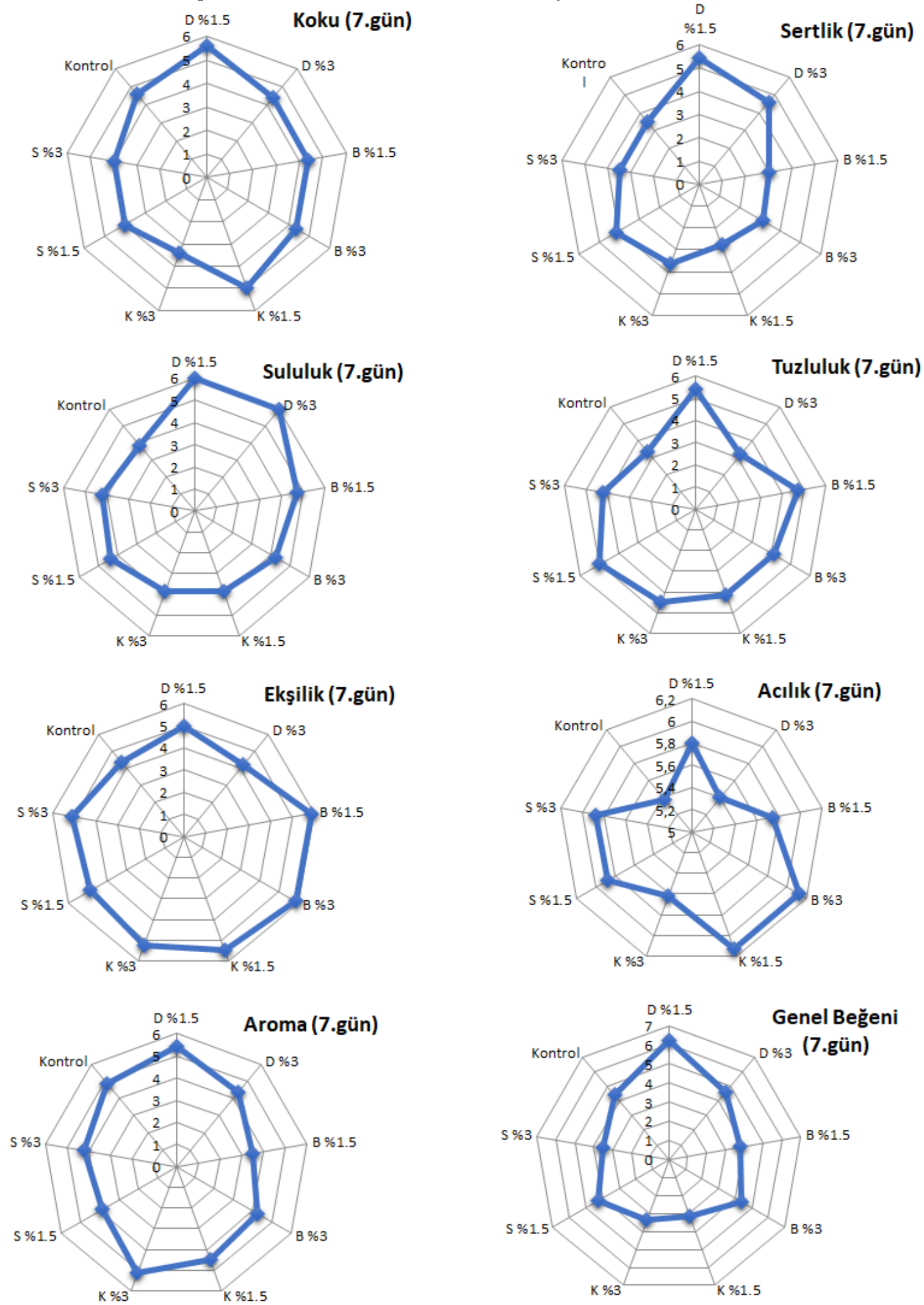

*Verilen diyagramda D: Defneyaprağı, B: Biberiye, K: Kekik, S: Sumak bitkilerini göstermektedir. \%1.5 ve 3 ilave oranlarını temsil etmektedir. 
Şekil 2. Depolamanın 14. Gününde Örneklerin Duyusal Analiz Sonuçları*
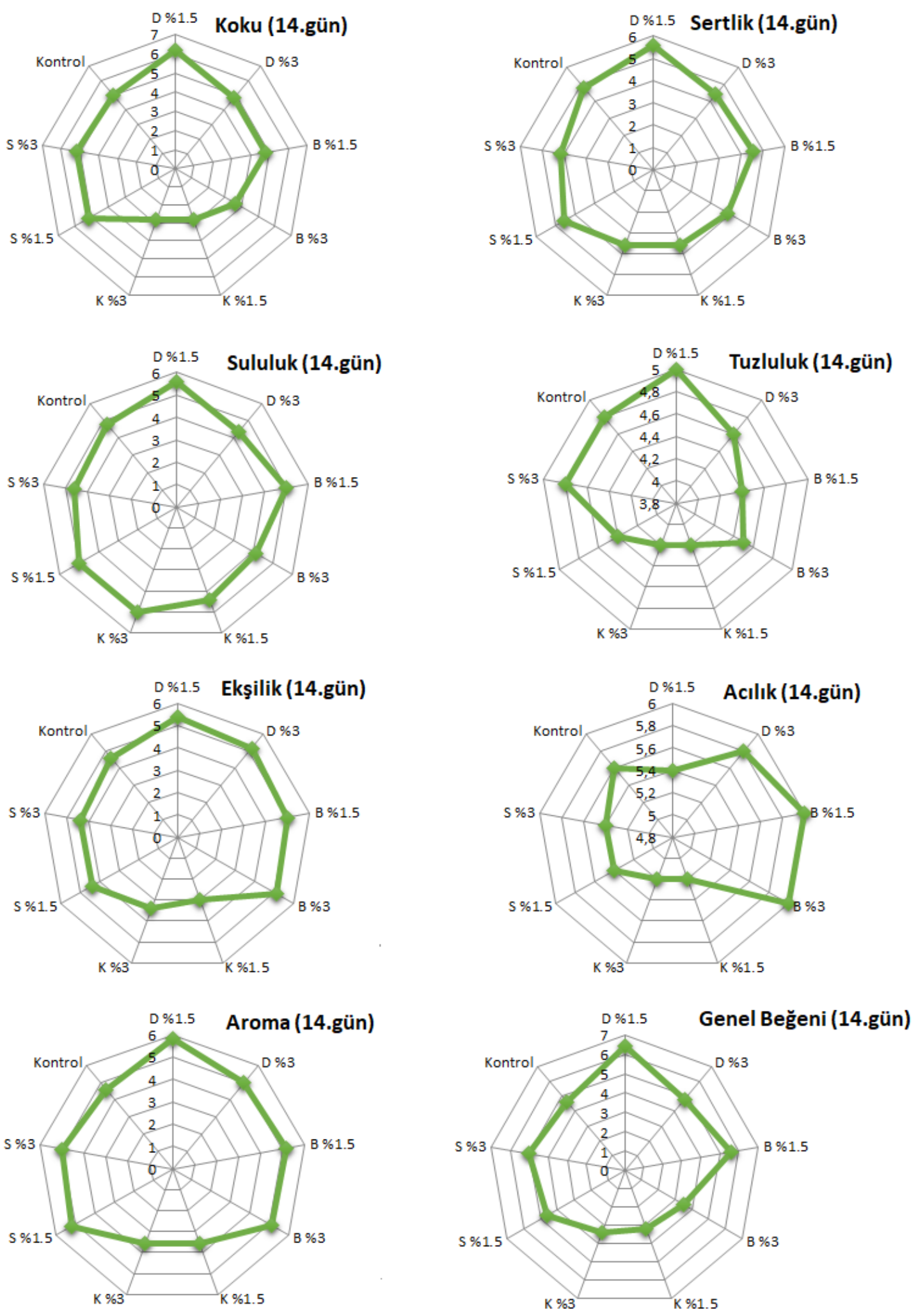

*Verilen diyagramda D: Defneyaprağı, B: Biberiye, K: Kekik, S: Sumak bitkilerini göstermektedir. \%1.5 ve 3 ilave oranlarını temsil etmektedir. 
Duyusal sonuçlara göre koku kriteri incelendiğinde en yüksek skoru \%1.5 defne ilave edilen ve 14 gün depolanan örnek almıştır. En düşük skor ise 14 gün depolanan kekik örneklerinde görülmüştür. Sonuçlara göre uzun depolama süreleri kekik bitkisinin, ette duyusal kaliteyi düşürdügü söylenebilir. Bunun aksi olarak defneyaprağının ilave oranına bakılmaksızın 14 gün depolamada koku kriteri duyusal puanları yükselmiştir. Yine sertlik ve sululuk parametreleri göz önüne alındığında defneyaprağı ilave edilen örnekler ön sıradadır. Aroma özelliklerine bakıldığında en yüksek skor defneyaprağına ait iken en düşük skor biberiye ve kekik bitkisine aittir. Genel beğeni kriteri incelendiğinde 7 ve 14 günlük depolamada \%1.5 defneyaprağ 1 ilave edilen örnekler en yüksek puanı almıştır.

Tablo 4. Depolamanın 7.gününde Örneklerin SAW Tekniğine Göre İkili Karşılaştırma Matrisi

\begin{tabular}{|c|c|c|c|c|c|c|c|c|c|c|c|}
\hline & \multicolumn{4}{|c|}{ Normalize Karar Matrisi } & \multicolumn{5}{|c|}{ Ağırlıklandırılmış Karar Matrisi } & \multirow[b]{2}{*}{ K } & \multirow[b]{2}{*}{ Toplam } \\
\hline & GB & SE & $\mathbf{A}$ & $\mathrm{S}$ & $\mathbf{K}$ & GB & SE & A & $S$ & & \\
\hline Kontrol & 0.165 & 0.161 & 0.134 & 0.145 & 0.141 & 0.059 & 0.045 & 0.027 & 0.017 & 0.006 & 0.154 \\
\hline Sumak \% 1.5 & 0.122 & 0.137 & 0.110 & 0.145 & 0.111 & 0.044 & 0.038 & 0.022 & 0.017 & 0.004 & 0.126 \\
\hline Sumak \% 3 & 0.100 & 0.089 & 0.087 & 0.115 & 0.110 & 0.036 & 0.025 & 0.017 & 0.014 & 0.004 & 0.097 \\
\hline \multicolumn{12}{|l|}{ Defneyaprağı } \\
\hline$\% 1.5$ & 0.116 & 0.093 & 0.106 & 0.103 & 0.110 & 0.042 & 0.026 & 0.021 & 0.012 & 0.004 & 0.106 \\
\hline \multicolumn{12}{|l|}{ Defneyaprağ1 } \\
\hline$\% 3.0$ & 0.083 & 0.082 & 0.112 & 0.094 & 0.126 & 0.030 & 0.023 & 0.022 & 0.011 & 0.005 & 0.092 \\
\hline Kekik \% 1.5 & 0.090 & 0.108 & 0.128 & 0.094 & 0.085 & 0.032 & 0.030 & 0.026 & 0.011 & 0.003 & 0.103 \\
\hline Kekik \% 3.0 & 0.113 & 0.123 & 0.096 & 0.106 & 0.101 & 0.041 & 0.034 & 0.019 & 0.013 & 0.004 & 0.111 \\
\hline \multicolumn{12}{|l|}{ Biberiye \% } \\
\hline 1.5 & 0.093 & 0.104 & 0.106 & 0.103 & 0.101 & 0.034 & 0.029 & 0.021 & 0.012 & 0.004 & 0.100 \\
\hline \multicolumn{12}{|l|}{ Biberiye \% } \\
\hline 3.0 & 0.117 & 0.104 & 0.121 & 0.094 & 0.116 & 0.042 & 0.029 & 0.024 & 0.011 & 0.005 & 0.111 \\
\hline
\end{tabular}

GB:Genel beğeni, SE:Sertlik, A:Aroma, S:Sululuk, K:Koku duyusal parametrelerini ifade etmektedir. D: Defneyaprağı, B: Biberiye, K: Kekik, S: Sumak bitkilerini göstermektedir.

Tablo 4'de SAW yöntemine göre genel beğeni, sertlik, aroma, sululuk ve koku duyusal değerlendirmeleri baz alınarak en tercih edilen et örneklerinin 7.gün sonundaki karar matrisleri görülmektedir. Toplam sütunu incelendiğinde 7. gün depolaması sonucunda en beğenilen ürünün defneyaprağının \%1.5 oranında katıldığı örnek olduğu, en az beğenilen ürünün ise \% 1.5 oranında kekik ilavesi ile elde edilen et örnekleri olarak tespit edilmiştir. 
Tablo 5. Depolamanın 14.gününde Örneklerin SAW Tekniğine Göre İkili Karşılaştırma Matrisi

\begin{tabular}{lllllllllllll}
\hline & \multicolumn{1}{l}{ Normalize Karar Matrisi } & \multicolumn{7}{c}{ Ağırlılandırılmıs Karar Matrisi } \\
\hline & GB & SE & A & S & K & GB & SE & A & S & K & Toplam \\
Kontrol & 0.156 & 0.143 & 0.134 & 0.130 & 0.153 & 0.056 & 0.040 & 0.027 & 0.016 & 0.006 & 0.145 \\
Sumak \% 1.5 & 0.117 & 0.112 & 0.116 & 0.103 & 0.119 & 0.042 & 0.031 & 0.023 & 0.012 & 0.005 & 0.114 \\
Sumak \% 3 & 0.136 & 0.117 & 0.121 & 0.116 & 0.119 & 0.049 & 0.033 & 0.024 & 0.014 & 0.005 & 0.125 \\
Defneyaprağ1 \% & & & & & & & & & & & \\
$\mathbf{1 . 5}$ & 0.085 & 0.099 & 0.119 & 0.096 & 0.090 & 0.031 & 0.028 & 0.024 & 0.012 & 0.004 & 0.097 \\
Defneyaprağ1 \% & & & & & & & & & & & \\
3.0 & 0.078 & 0.092 & 0.083 & 0.103 & 0.069 & 0.028 & 0.026 & 0.017 & 0.012 & 0.003 & 0.085 \\
Kekik \% 1.5 & 0.083 & 0.092 & 0.083 & 0.116 & 0.069 & 0.030 & 0.026 & 0.017 & 0.014 & 0.003 & 0.089 \\
Kekik \% 3.0 & 0.112 & 0.117 & 0.121 & 0.116 & 0.129 & 0.040 & 0.033 & 0.024 & 0.014 & 0.005 & 0.116 \\
Biberiye \% 1.5 & 0.122 & 0.107 & 0.116 & 0.107 & 0.129 & 0.044 & 0.030 & 0.023 & 0.013 & 0.005 & 0.115 \\
Biberiye \% 3.0 & 0.112 & 0.122 & 0.107 & 0.112 & 0.124 & 0.040 & 0.034 & 0.021 & 0.013 & 0.005 & 0.114 \\
\hline
\end{tabular}

GB:Genel beğeni, SE:Sertlik, A:Aroma, S:Sululuk, K:Koku duyusal parametrelerini ifade etmektedir. D: Defneyaprağı, B: Biberiye, K: Kekik, S: Sumak bitkilerini göstermektedir.

SAW yöntemi ile 14.gün depolama sonucunda örneklerin duyusal analiz sonuçları değerlendirildiğinde, 7.gün depolamasında olduğu üzere yine aynı oranlara sahip ürünler en beğenilen ve beğenilmeyen ürünler olduğu belirlenmiştir.

\section{SONUÇ ve ÖNERILER}

Çalışma kapsamında farklı konsantrasyonda ve farklı bitkilerle marine edilerek depolanan vakumlu etlerin bazı kalite özellikleri incelenmiştir. Analizlerin tamamı incelendiğinde defneyaprağı ile marine edilen etlerin hem kimyasal hem de duyusal analiz sonuçlarının diğer örneklere göre daha olumlu olduğu düşünülebilir. Vakumlu ambalajlanmış etlerin 14 gün sonundaki duyusal kalite parametreleri göz önünde bulundurulduğunda, defneyaprağı en beğenilen marinasyon bitkisi olduğu görülmüştür.

Bu kapsamda yiyecek içecek işletmelerinin et marinasyonunda defne yaprağını kullanmaları, tüketicilerin beğeni düzeylerini yükselttiği gibi kimyasal yönden daha sağllklı üretim yapmalarına vesile olabilecektir. Böylece müşterilerine marine edilmiş et yemekleri sunan işletmeleri hem daha lezzetli hem daha uzun raf ömrü olan yemekler ile müşteri memnuniyetini artıracakları tavsiye edilebilir. 


\section{KAYNAKLAR}

Akgül, A. ve Ayar, A. (1993). Yerli baharatların antioksidan etkileri. Doğa-TR. J. of Agriculture and Forestry,17: 1061-1068.

Aymerich, T., Picouet, P. A. and Monfort, J. M. (2008). Decontamination technologies for meat products. Meat Science. 78, 114-129.

Babür, T. E. ve Gürbüz, Ü. (2015). Geleneksel Pişirme Yöntemlerinin Et Kalitesine Etkileri. Journal of Tourism and Gastronomy Studies. 2015 (3/4) 58-64.

Bayaz, M., (2014). Esansiyel Yağlar: Antimikrobiyal, Antioksidan ve Antimutajenik Aktiviteleri. Akademik Gıda. 12(3):45-53.

Candoğan, K. and Kolsarıcı, N. (2003) Storage stability of low-fat beef franfurter formulated with carragenan or carregenan with pectin. Meat Science. 64, 207-214.

Churchman, C.W. and Ackoff, R.L. (1954). An approximate measure of value. Journal of the Operations Research Society of America. 2 (2): 172-187.

Devlieghere, F., Vermeiren, L. and Debevere, J. (2004). New preservation technologies: Possibilities and limitations. International Dairy Journal. 14: 273-285.

Dogan, M., Aslan, D., Aktar, T. and Goksel Sarac, M. (2016). A methodology to evaluate the sensory properties of instant hot chocolate beverage with different fat contents: multi-criteria decision-making techniques approach. European Food Research Technology. 242 (6): 953-966.

Doğan, Ö. (2019). Et nasıl marine edilir?, Blog, Yemek.com, yemek.com/et-nasil-marine-edilir. Erişim: Aralık, 2019.

EFSA (European Food Safety Authority) (2011). The European Union summary report on trends and sources of zoonoses, zoonotic agents and food-borne outbreaks in 2009.

Faustmann, C. and Cassens, R. G. (1990). The biochemical basis for discoloration in fresh meat: a review. Journal of Muscle Foods. 1 (3): 217-243.

Fernandez, J., Perez-Alvarez, J. A. and Fernandez-Lopez, J. A. (1997). Thiobarbituric acid test for monitoring lipid oxidation in meat. Food Chemistry. 59(3), 345-353

Fishburn, P.C. (1967). Additive Utilities with Incomplete Product Sets: Application to Priorities and Assignments. Operations Research. 15, (3): 537-542.

Gwo-Hshiung, T. and Huang J.J. (2010). Multiple attribute decision making: methods and applications. CRC Press. $335 \mathrm{~s}$.

Hastaoğlu, E. (2019). Doğal esansiyel yağlar ve doğal ekstraktlar ile emülsifiye et ürünleri üretimi ve kalite özelliklerinin incelenmesi, Doktora Tezi, Hacettepe Üniversitesi, Ankara.

ISO2917 pH Ölçülmesi Standardı.

Iwasaki, M., Kataoka, H., Ishihara, J., Takachi, R., Hamada, G., Sharma, S., Marchand, L. and Tsugane S, (2010). Heterocyclic amines content of meat and fish cooked by Brezillian methods. Journal of Food Composition and Analysis. 23, 61-69. 
Kahraman, T., Bayraktaroğlu, A.G., Issa, G. ve Aksu, F. (2010). Bazı organik asitlerle yapılan marinasyon işleminin sığır et kalitesi üzerine etkisi. İstanbul Üniversitesi Veterinerlik Fakültesi Dergisi, 36 (2), 25-31.

Karabudak, E. (2002). Etlerdeki lipid peroksidasyonunun bir ürünü olarak malonaldehid ve ölçüm yöntemleri. Beslenme ve Diyet Dergisi, 31(1): 43-48,

Lemos, A. L. S. C., Nunes, D. R. M. and Viana A.G. (1999). Optimization of the Still-marinating Process of Chicken Parts. Meat Science. 52: 227-234.

Miguel, G., Simoes, M., Figueiredo, A. C., Barroso, J. G., Pedro, L. G. and Carvalho, L. (2004). Composition and antioxidant activities of the essential oils of Thymus caespititius, Thymus camphoratus and Thymus mastichina. Food Chemistry. 86:183-188.

Özcan, M. and Sağdıç, O. (2003). Antibacterial activity of Turkish spice hydrosols. Food Control. 14: 141-143.

Öztan, A. (2018). Et Bilimi ve Teknolojisi, TMMOB Gıda Mühendisleri Odası Yayınları, Ankara.

Schmedes, A., Hølmer, G. (1989). A new thiobarbituric acid (TBA) method for determining free malondialdehyde (MDA) and hydroperoxides selectively as a measure of lipid peroxidation, $J$. Am. Oil Chem. Soc. 66: 813-817.

Serrano, A., Librelotto, J., Cofrades, S., Sánchez-Muniz, F. J. and Jiménez-Colmenero, F. (2007). Composition and physicochemical characteristics of restructured beef steaks containing walnuts as affected by cooking method. Meat Science. 77, 304-313.

Smith, D. (1999). Marination Tender to the Bottom Line. Broiler Industry. 62 (6): 22, 24-27.

Smith, D. P. and J. C. Acton. (2001). Marination, cooking, and curing of poultry products. Pages 257-281, chapter 15 in Poultry Meat Processing. A. R. Sams, ed. CRC Press, Boca Raton, FL.

Vazgeçer, B., Ulu, H. ve Öztan, A. (2005). Et ve et ürünlerinde baharatın antioksidan ve antimikrobiyal aktivitesi. Gıda. 30(2), 75-81.

Vural, H. ve Öztan A. (1996). Et ve Ürünleri Kalite Kontrol Laboratuarı Uygulama Kılavuzu, Hacettepe Üniversitesi Mühendislik Fakültesi Yayınları No: 36, Ankara.

Woods, L. F. C. and Church, P. N. (1999). Strategies for Extending the Shelf Life of Poultry Meat and Products. Poultry Meat Science. Vol. 25 Cabi Publishing. Oxfordshire. 297-311.

Xargayo, M., Lagares, J., Fernandez, E., Ruiz, D. and Borell, D. (2001). Marination of Fresh Meats by Means of Spray Effect: Influence of Spray Injection on the Quality of Marinated Products. Fleischwirtschaft International. 81(2) 93-98.

Yanishlieva, N.V. and Marinova, E. M. (2001). Stabilisation of edible oils with natural antioxidants. Eur. Journal Lipid Science Technol. 103, 752-767. Complementary Therapies Part 2: Vol. 10, No. 5: 277-284.

Yapar, F. (2006). Parça et ve kıymalarda erik ekşisi, nar ekşisi ve limon tuzunun antibakteriyal etkisi. Çukurova Üniversitesi Fen Bilimleri Enstitüsü, Yüksek Lisans Tezi.

Zhou, G. H., Xu, X. L. and Liu, Y. (2010). Preservation technologies for fresh meat - A review. Meat Science. 86: 119-128. 